Pacific Journal of Mathematics

ON THE STRUCTURE OF PRINCIPAL IDEAL RINGS 


\title{
ON THE STRUCTURE OF PRINCIPAL IDEAL RINGS
}

\author{
THOMAS W. HUNGERFORD
}

In this paper all rings are supposed commutative with identity (and all ring direct sums are finite). We distinguish between a principal ideal domain (PID) and a principal ideal ring (PIR) which may not be an integral domain. Our chief purpose is to prove:

Theorem 1. Every principal ideal ring $R$ is a direct sum of rings, each of which is the homomorphic image of a principal ideal domain.

A number of special cases of this theorem are well known. In order to prove the general case one needs several facts about complete local rings and formal power series rings. For the reader's convenience, this background material is summarized in $\S 1$; the theorem is proved in $\S 2$. In the final section is shown a counterexample indicating that in a sense Theorem 1 is best possible.

\section{Preliminaries.}

DEFINITION 2. A Noetherian ring $R$ which has a unique maximal ideal $M$ is a local ring.

The following proposition, a proof of which is in Lambek [5, p. 34], is extremely useful for characterizing local rings.

Proposition 3. The following conditions on a ring $R$ are equivalent:

(1) $R$ has a unique maximal ideal $M$;

(2) all nonunits of $R$ are contained in a proper ideal $M$;

(3) the nonunits of $R$ form an ideal $M$.

If $R$ is a local ring, then $\bigcap_{i \geq 1} M^{i}=0$; this fact is due to Krull [3, Th. 2] and is also proved in Nagata [6, p. 12]. Consequently we obtain

Proposition 4. Let $R$ be a local ring whose maximal ideal $M$ is principal, $M=(a)$, then $R$ is a principal ideal ring and every nonzero element of $R$ can be written in the form $a^{k} u$, with $u$ a unit.

Proof. Let $r \in R$. Since $\bigcap M^{i}=\bigcap\left(a^{i}\right)=0$, there is a highest power of a dividing $r$, say $r=a^{k} u$. Then $u$ must be a unit, since all nonunits are in $M$ and $u \in M$ implies $a \mid u$, hence $a^{k+1} \mid r$. If $J$ is any ideal in $R$, all elements of $J$ can be written in the form $a^{i} u, u$ a unit. Choose such an element with $i$ minimal. It is then easy to 
verify that $J=\left(a^{i}\right)$.

A standard procedure with a local ring $R$ (maximal ideal $M$ ) is to topologize it by taking the family $\left\{M^{i} \mid i \geqq 1\right\}$ as a base of neighborhoods of 0 in $R$. It can be verified that this topology agrees with the topology induced by the following metric on $R: d(r, r)=0$; $d(r, s)=2^{-n}$ if and only if $r-s \in M^{n}$ and $r-s \notin M^{n+1}$. A complete local ring is a local ring which is complete with respect to this topology. The structure of complete local rings is well known and will be described in Theorem 8 below.

If $R$ is any ring, $R[[x]]$ denotes the ring of formal power series in one indeterminate with coefficients in $R$. The ring of polynomials $R[x]$ is considered as a subring of $R[[x]]$ in the obvious way. We shall need several facts about such power series.

Proposition 5. Let $R$ be a ring. Then:

(1) If $R$ is an integral domain, so is $R[[x]]$;

(2) If $R$ is Noetherian, so is $R[[x]]$;

(3) An element $f \in R[[x]]$ is a unit if and only if the constant term of $f$ if a unit in $R$.

The proofs of (1)-(3) can be found in Zariski and Samuel [8, Chapter 7] and in Nagata [6, Chapter 2].

Corollary 6. If $R$ is a field, then $R[[x]]$ is a principal ideal domain.

Proof. All nonzero elements of a field are units; hence (3) implies that all the nonunits of $R[[x]]$ are contained in the ideal $(x)$. Hence by (1), (2) and Proposition $3 R[[x]]$ is a local integral domain whose maximal ideal is principal. Therefore by Proposition $4 R[[x]]$ is a principal ideal domain.

It should also be noted that (3) implies that every element of $R[[x]]$ whose constant term is irreducible in $R$ is irreducible in $R[[x]]$.

Definition 7. A v-ring is a ring $D$ such that $D$ is a complete local integral domain of characteristic zero, whose maximal ideal $N$ is generated by $p$ (the $p$-fold of the identity element-i.e. $1+1+\cdots+1$ ( $p$ times)), where $p \neq 0$ is the characteristic of the residue field $D / N$.

By Proposition 4, a $v$-ring $D$ is a PID. Observe that (up to unit) $p$ is the only irreducible element of $D$.

THEOREM 8. Let $R$ be a complete local ring whose maximal ideal $M$ is principal, $M=(a)$. Then $R$ is the homomorphic image of $D[[x]]$ under a homomorphism which sends $x \in D[[x]]$ onto $a \in R$, where 
$D$ is either the field $R / M$ (if char $R=$ char $R / M$ ), or a v-ring whose residue field $D /(p)$ is naturally isomorphic to $R / M$ (if char $R \neq$ char $R / M)$.

This is a very specialized version of the structure theorem for complete local rings due to Cohen [1, Theorem 9 and 12].

\section{Proof of Theorem 1 .}

DEFINITION 9. A principal ideal ring $R$ is special if $R$ has a unique prime ideal and this ideal is nilpotent.

Since every PIR is Noetherian and every maximal ideal is prime, a special PIR is a local ring. Furthermore the nilpotency of the maximal ideal implies that every Cauchy sequence must eventually be constant and therefore convergent. Hence a special PIR is a complete local ring.

Lemma 10. Every principal ideal ring $R$ is the direct sum of principal ideal domains and special principal ideal rings.

This is just Theorem 33, page 245, of Zariski and Samuel [7]. In view of the lemma it suffices in Theorem 1 to assume that $R$ is a special PIR and thus a complete local ring with (nipotent) maximal ideal $M=(a)$. By Theorem $8, R$ is the homomorphic image of $D[[x]]$, where $D$ is a field or $v$-ring. If $D$ is a field $D[[x]]$ is a PID by Corollary 6. If $D$ is a $v$-ring, $D[[x]]$ is not a PID. Consequently, to complete the proof of Theorem 1 we must show that when $D$ is a $v$-ring, $R$ is the homomorphic image of a PID.

Let $\varphi: D[[x]] \rightarrow R$ be a ring epimorphism such that $\varphi(x)=a$. Our method is to factor out of $D[[x]]$ a principal ideal generated by an irreducible element in such a way that the resulting quotient is a PID. We shall choose this irreducible element to be in kernel $\varphi$. Thus $\varphi$ will induce a homomorphism from the quotient onto $R$ and the theorem will be proved.

As above we shall write $p$ for the ordinary prime integer as well as for the $p$-fold of the identity in $R$ and in $D$ (and therefore also in $D[[x]])$. In the present case $D$ is a $v$-ring and by Theorem 8 we have: $\operatorname{char} R \neq \operatorname{char} R / M=\operatorname{char} D /(p)=p \neq 0$. It follows that $p \in R$ is a nonzero nonunit. Therefore by Proposition $4, p$ can be written in the form $a^{k} u$, with $u$ a unit in $R ; k>0$ since $p$ is in the ideal of nonunits $M=(a)$. Choose $c \in D[[x]]$ such that $\varphi(c)=u$. Then the element $f=-c x^{k}+p$ of $D[[x]]$ is in the kernel of $\varphi$ (since $\varphi(x)=a$ and $\varphi(p)=p)$. Furthermore since the constant term of $f$ is $p$, which is irreducible in $D, f$ is irreducible in $D[[x]]$. 
It is proved in Krull [4, p. 13] that if $D$ if a $v$-ring, then $D[[x]]$ is a unique factorization domain. Therefore the ideal $(f)$ generated by the irreducible element $f$ is a prime ideal (see, for example, Zariski and Samuel [7, p. 21]). Thus the quotient $S=D[[x]] /(f)$ is an integral domain and $\varphi: S \rightarrow R$ is an epimorphism.

To complete the proof we need only show that $S$ is a PID. By Proposition 4 this will be the case if we can show that $S$ is a local ring with principal maximal ideal. $D[[x]]$ (and hence $S$ ) is Noetherian by Proposition 5. If $h \in D[[x]]$ let $\bar{h}$ denote its coset in $S$. Since $\varphi(\bar{x})=a$, which is a nonunit in $R, \bar{x}$ must be a nonunit in $S$. Therefore $(\bar{x})$ is a proper ideal in $S$. Also since $\bar{f}=0$ in $S$ and $f$ has constant term $p, \bar{p} \in(\bar{x})$. Now let $\bar{h}$ be a nonunit in $S$. Then $h$ is a nonunit in $D[[x]]$ and therefore has constant term which is a nonunit in $D$. Since $(p)$ is the ideal of all nonunits in $D$, the constant term of $h$ is in $(p)$. But then $h$ is a sum of an element in $(x)$ and an element in $(p)$. Therefore $\bar{h}$ is the sum of an element in $(\bar{x})$ and an element in $(\bar{p}) \subseteq(\bar{x})$. Hence $\bar{h} \in(\bar{x})$ and $(\bar{x})$ contains all nonunits of $S$. Thus by Proposition $3 S$ is a local integral domain with principal maximal ideal. By Proposition 4, $S$ is a PID and the proof is complete.

COROLLARY 11. Every special principal ideal ring is the homomorphic image of a principal ideal domain.

3. Further comments. In a certain sense, Theorem 1 is best possible. Namely the following conjecture is false: every principal ideal ring is the homomorphic image of a principal ideal domain. A counterexample to this conjecture is given by the direct sum $S=R \oplus Z$ of the reals and the integers. $S$ is clearly a PIR which is not an integral domain. Also every $Z$-module is an $S$-module by pullback along the projection $R \oplus Z \rightarrow Z$. In particular the additive group of rationals $Q$ is an $S$-module. As is well known $Q$ is not a direct sum of cyclic groups, and hence cannot be a direct sum of cyclic $S$-modules.

Suppose $S$ were a proper quotient of an integral domain $D$, say $S=D /(c)$. Then every $S$-module is also a $D$-module which is annihilated by the ideal $(c)$. Thus every $S$-module is a torsion $D$-module of bounded order and therefore by Kaplansky [2, Th. 6 and p. 36] is a direct sum of cyclic $D$-modules. Therefore every $S$-module, (in particular $Q$ ) is also a direct sum of cyclic $S$-modules, a contradiction.

In closing we note the following easy consequence of Lemma 10.

CoROLlary 12. A principal ideal ring $R$ is a direct sum of principal ideal domains if and only if it has no nonzero nilpotent elements. 


\section{BIBLIOGRAPHY}

1. I. S. Cohen, On the structure and ideal theory of complete local rings, Trans. Amer. Math. Soc. 59 (1946), 54-106.

2. I. Kaplansky, Infinite Abelian Groups, University of Michigan Press, Ann Arbor, 1954.

3. W. Krull, Dimensionstheorie in Stellenringen, J. Reine Angew. Math. 179 (1938), 204-226.

4. - Uber die Zerlegung der Hauptideale in allgemeinen Ringen, Math. Ann. 105 (1931), 1-14.

5. J. Lambek, Lectures on Rings and Modules, Blaisdell, Waltham, Toronto, and London, 1966.

6. M. Nagata, Local Rings, Interscience, New York and London, 1962.

7. O. Zariski and P. Samuel, Commutative Algebra, volume I, Van Nostrand, Princeton, 1960.

8. - Commutative Algebra, volume II, Van Nostrand Princeton, 1960.

Received July 27, 1967.

UNIVERSITY OF WASHINGTON 



\title{
PACIFIC JOURNAL OF MATHEMATICS
}

\author{
EDITORS
}

\section{H. ROYDEN}

Stanford University

Stanford, California

\author{
J. P. JANS \\ University of Washington \\ Seattle, Washington 98105
}

\section{J. DugundJI}

Department of Mathematics

University of Southern California

Los Angeles, California 90007

\section{RICHARD ARENS}

University of California

Los Angeles, California 90024

\section{ASSOCIATE EDITORS}
E. F. BECKENBACH
B. H. NEUMANN
F. WOLF
K. YOSIDA

\section{SUPPORTING INSTITUTIONS}

\author{
UNIVERSITY OF BRITISH COLUMBIA \\ CALIFORNIA INSTITUTE OF TECHNOLOGY \\ UNIVERSITY OF CALIFORNIA \\ MONTANA STATE UNIVERSITY \\ UNIVERSITY OF NEVADA \\ NEW MEXICO STATE UNIVERSITY \\ OREGON STATE UNIVERSITY \\ UNIVERSITY OF OREGON \\ OSAKA UNIVERSITY \\ UNIVERSITY OF SOUTHERN CALIFORNIA
}

\author{
STANFORD UNIVERSITY \\ UNIVERSITY OF TOKYO \\ UNIVERSITY OF UTAH \\ WASHINGTON STATE UNIVERSITY \\ UNIVERSITY OF WASHINGTON \\ AMERICAN MATHEMATICAL SOCIETY \\ CHEVRON RESEARCH CORPORATION \\ TRW SYSTEMS \\ NAVAL WEAPONS CENTER
}

Mathematical papers intended for publication in the Pacific Journal of Mathematics should be in typed form or offset-reproduced, double spaced with large margins. Underline Greek letters in red, German in green, and script in blue. The first paragraph or two must be capable of being used separately as a synopsis of the entire paper. It should not contain references to the bibliography. Manuscripts, in duplicate if possible, may be sent to any one of the four editors. All other communications to the editors should be addressed to the managing editor, Richard Arens, University of California, Los Angeles, California 90024.

Each author of each article receives 50 reprints free of charge; additional copies may be obtained at cost in multiples of 50 .

The Pacific Journal of Mathematics is published monthly. Effective with Volume 16 the price per volume (3 numbers) is $\$ 8.00$; single issues, $\$ 3.00$. Special price for current issues to individual faculty members of supporting institutions and to individual members of the American Mathematical Society: $\$ 4.00$ per volume; single issues $\$ 1.50$. Back numbers are available.

Subscriptions, orders for back numbers, and changes of address should be sent to Pacific Journal of Mathematics, 103 Highland Boulevard, Berkeley 8, California.

Printed at Kokusai Bunken Insatsusha (International Academic Printing Co., Ltd.), 7-17, Fujimi 2-chome, Chiyoda-ku, Tokyo, Japan.

PUBLISHED BY PACIFIC JOURNAL OF MATHEMATICS, A NON-PROFIT CORPORATION

The Supporting Institutions listed above contribute to the cost of publication of this Journal, but they are not owners of publishers and have no responsibility for its content or policies. 


\section{Pacific Journal of Mathematics}

\section{Vol. 25, No. $3 \quad$ November, 1968}

Philip Marshall Anselone and Theodore Windle Palmer, Collectively

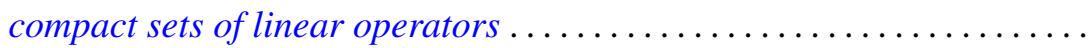

Philip Marshall Anselone and Theodore Windle Palmer, Spectral analysis of collectively compact, strongly convergent operator sequences.........

Edward A. Bender, Characteristic polynomials of symmetric matrices...... 433

Robert Morgan Brooks, The structure space of a commutative locally convex

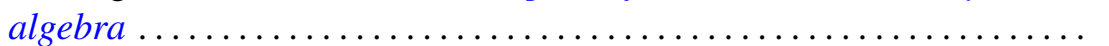

Jacob Feldman and Frederick Paul Greenleaf, Existence of Borel

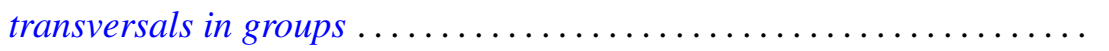

Thomas Muirhead Flett, Mean values of power series 463

Richard Vernon Fuller, Relations among continuous and various

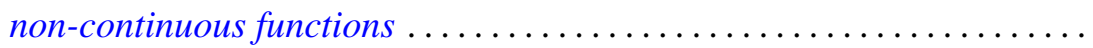

Philip Hartman, Convex sets and the bounded slope condition ............

Marcel Herzog, On finite groups containing a CCT-subgroup with a cyclic Sylow subgroup .

James Secord Howland, On the essential spectrum of Schroedinger

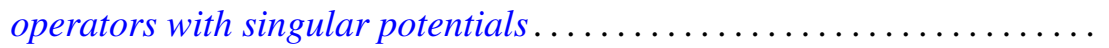

Thomas William Hungerford, On the structure of principal ideal rings .....

Paul Joseph Kelly and Ernst Gabor Straus, Curvature in Hilbert geometries. II mpati Madhusudana Rao, Linear functionals on Orlicz spaces:

Malempati Madhusudana Rao, Linear functionals on Orli
$\quad$ General theory............................
Stanley F. Robinson, Theorems on Brewer sums.......
Ralph Tyrrell Rockafellar, A general correspondence betw

Malempati Madhusudana Rao, Linear functiona
$\quad$ General theory.........................
Stanley F. Robinson, Theorems on Brewer sums
Ralph Tyrrell Rockafellar, A general corresponden

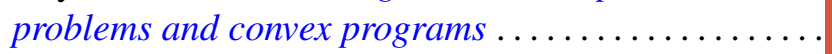

Richard Benjamin Sher, Defining subsets of $E^{3}$ by cubes.

Howard Jacob Weiner, Invariant measures and Cesàro summability... 